\title{
Risk Analysis of Investments In-Milk Collection Centers
}

\author{
Kheiry Hassan M. Ishag ${ }^{1}$ \\ ${ }^{1}$ Dhofar Cattle Feed Company, P.O. Box 1220, PC 211, Sultanate of Oman \\ Correspondence: Kheiry Hassan M. Ishag, Dhofar Cattle Feed Company, P.O. Box 1220, PC 211, Sultanate of \\ Oman. Tel: 968-994-90564. E-mail: kheiryishag@hotmail.com
}

\author{
Received: April 1, 2015 Accepted: April 19, 2015 Online Published: April 20, 2015 \\ doi:10.5539/sar.v4n2p104 URL: http://dx.doi.org/10.5539/sar.v4n2p104
}

\begin{abstract}
Milk marketing in rural area of Dhofar Region face a lot of difficulties and constrains by individual small scale farmers due to the lack of facilities and access to market. Therefore, farmers reduce their cow and camel milk production and group their animal into three or four groups to be milked in alternative days. Government Authorities decided to establish Milk Collection Centers to facilitate milk marketing and provide raw milk to Dairy industries. A risk analysis for the investment in milk collection centers on rural area of Dhofar Region was conducted in this study. The results showed that all MCC investments had a positive NPV except Shahbi Aseab Center. The study indicates there is a direct relationship between total milk collected, milk price, distant between MCC and Dairy plan and investment profitability. The study revealed an inverse relation between animal population at MCC zone and risk. The probability of achieving returns lower than the opportunity cost was highest for MCC located far from dairy plant which process and market dairy products. Risk premium for four MCC has been calculated relative to Salalah MCC (preferred location) and (Garoun Hirity MCC) was found as preferred MCC location and risk efficiency. In order to make the investment in MCC more attractive, the Government incentives need to be offered to farmers to increase milk production and improve raw milk quality. However, this approach might make investments in bulk milk collection centers feasible. Thus, a recommendable strategy for a successful modernization of the Oman dairy sectors inbound logistics would be to promote an increase in the volume of the milk produced per farm and improve marketing facilities through MCC.
\end{abstract}

Keywords: Milk Collection Centre MCC, NPV, risk analysis, SERF risk efficiency analysis, Cumulated Distribution Function analysis

\section{Introduction}

Dairy products are currently one of the main sources of income for a significant share of the Omani farmers at Dhofar Region. In 2014, Oman dairy market is estimated of 167 Million liters per year with annual growth of 6\% and only $30 \%$ of the demand produced by local dairy plant based at Dhofar Region. Due to lack of facilities and access to market, farmers reduce their cow and camel milk production and group their animal into three or four groups to be milked in alternative days. Government Authorities decided to establish Milk Collection Centers to facilitate milk marketing and provide raw milk to Dairy industries.

Changes in the country's economic environment over the last decade such as market openings and economic stability etc. have made it crucial that the dairy business sector need to be modernized and become more competitive. Operating costs need to be reduced and raw material quality needs to be improved to achieve these goals. The milk collection systems needs to be implemented and being put into operation. Using these MCC systems, milk has to be collected and cooled to $6^{\circ}$ at each MCC. The raw milk then collected daily by temperature controlled tank trucks to dairy plant for processing and marketing.

One of the probable consequences of the bulk milk collecting system is that it excludes remote areas and scattered small dairy farmers from the dairy business, since their output is considered insufficient to justify investment in MCC. As a contribution to the analysis of this issue, the present work assesses the risks involved in the installation and operation of five MCC at recommended location with appropriate animal population and density. The financial analysis of these investments was performed by (HVA International, 2010). However, this study did not consider risk analysis for this investment.

Volume of raw milk produced and collected is risk-dependent item since output depends on several factors, such as animal population at each location zone, climate \& rainy season, costs, and capital investments. Milk 
production in Dhofar Region is increases during the summer (rainy season) and decreases during the winter (dry season). This seasonal change is due to change in available pasture and fodder crop as more pasture in the summer, less in the winter. Farm investments to expand the herd, improve breeding stock, control diseases, and install milk cooling systems are economic factors that can contribute to increase milk production and assure raw milk quality.

Monte Carlo Simulation models were used in this study to quantify risk and uncertainty in milk collection project at Dhofar Region. The quantitative risk analysis will provide decision and policy makers a means of NPV estimating the probability that the project NPV will fall below zero. The model will also help in improving dairy sector management policy and achieve project objectives simultaneously: sustaining dairy business for food security and preserving the associated natural environment. Danielle D. et al. (2000), use Monte Carlo simulations to estimate profitability of different size of milk cooling tank under risky environment. In this study government subsidy and incentives at five locations were compared by performing dynamic location model.

Using Monte Carlo Simulation dynamic model for project appraisal was addressed by Savvakis C. Savvides in (1994). He argued that this integrated analysis provided a range of outcomes that can reduce the risk of uncertainty and give more reliable results for investor.

Stochastic efficiency with respect to a function (SERF) analysis, which is used in this study, has been used previously to evaluate crop production systems using net return distributions based on empirical data (Barham, Robinson, Richardson, \& Rister, 2011; Bryant et al., 2008; Hignight, Watkins, \& Anders, 2010; Pendell, Williams, Boyles, Rice, \& Nelson, 2007; Ribera, Hons, \& Richardson, 2004; Williams, Pachta, Claassen, Roozeboom, \& Llewelyn, 2011). SERF provides a more restrictive approach to compare risky alternative technologies by evaluating technology dominance across a wide range of plausible risk preferences.

To sum up, the analysis revealed that, although technologically and financially feasible, cooling tank investments are subject to uncertainties the effects of which can jeopardize efforts to modernize of milk collection system in rural area at Dhofar Region. These issues are discussed in depth in the following analysis.

\section{Materials and Methods}

Data collection and identification of the equipment needed for MCC were performed through direct contact with suppliers and producers who had already begun their milk collection systems modernization. The choice of tank sizes considered in this study was based on results of a comprehensive diagnostic and survey of the dairy milk production at farm level and dairy industry raw milk requirement.

In order to carry out a financial analysis, cash flows were built for the investment cost and expense and operation cost for each MCC. The main MCC investments were for cooling tanks purchase and the construction of milk receiving area and laboratories and connection of water and electricity.

The operation cost components were consumption of electric energy, consumption of detergents for tank sanitation, maintenance costs, labour cost, and milk transportation cost and investment depreciation. The price offered by dairies industry to farmers for cow and camel is 0.200 RO per Lit plus Government incentives: an additional $0.100 \mathrm{RO}$ per Lit added to the price paid for warm milk for supplying cooled milk. MCC will pay raw milk from farmers by (0.200) and sell it to dairy plant of (0.295). The cost of MCC operation is differing according to distant to dairy plant, milk volume and a reduction of $50 \%$ in the typical charge for using the traditional milk collection and transportation system for using the much less costly bulk transport system.

Based on the results from financial analysis, a sensitivity analysis of the investment was carried out, in which some parameters considered in the cash-flow estimation were varied. For each variation, a new net present value (NPV) was calculated for each MCC location. This produced a set of graphs known as Cumulated Distribution Function, which allow the assessment of the degree of uncertainty associated to each MCC investments. Gouse, M. et al. (2009). Assess GM Maize technology amongst smallholders in South Africa. The Cumulative distribution functions (CDFs) are used to compared yield and net returns. The CDFs analysis in this study used to identify the total milk collected revenue and expense items that had the most significant impacts on the financial indicators. The potential risks associated to these items are evaluated in detail in this study.

\subsection{Risk Analysis}

The financial analysis performed by (HVA International, 2010) considered that the project would be implemented with perfect control of its variables. However, due to uncertainties in the near future, this approach only approximates reality. In practice, project risks should be investigated, defined, and then controlled by policy makers and decision-makers. Risk is defined as the possibility of future loss in predicted return over a certain period of time (Palisade Corporation, 1995; Martins \& Assaf NETO, 1992). Current data is imperfect, future data 
even more imperfect. Every current business decision is associated to a series of hypotheses regarding future events (increase or decrease in raw milk prices, raw milk available at each MCC, climatic conditions, social and political events, etc). Even if prediction techniques were improved, they would not eliminate the uncertainty brought by unforeseen change in various factors affecting profitability. Szekres (1986) states that the decision to take risks depends on the utility function that each individual subjectively attributes to a particular situation. People react to risk with three general types of behavior, risk-avoidance, risk-indifference, or risk-orientation; and the decision-making process is directly related with one of these personal tendencies.

Although sensitivity analysis can point out the need for further study of uncertain variables, by itself it is not sufficient for the analysis of an investment projects risk. Firstly because sensitivity analysis is only a partial analysis, with only one variable considered at a time, it does not permit the negative effect caused by one variable to be counterbalanced by the positive effect from another. Secondly, the mere indication that a project is or is not sensitive to certain variables, though useful, does not satisfy the decision-maker. It is also important to have an idea of the probability of an adverse situation occurring, as well as this situations effect on project results (Noronha, 1987).

@ RISK (Palisade Corporation, 2010) software program was used for risk analysis in this study, and Monte Carlo simulation methodology was adopted. This methodology consists of simulating variables previously selected for the cash flow estimation and then calculating financial indicator values (IRR, net present value, etc.). After a number of random interactions, a frequency distribution of the financial indicator considered is generated result.

\subsection{Net Present Value}

The NPV was used as an evaluation criterion. The net cash flow, calculated by subtracting the cost from the revenue, was discounted by the interest rate to obtain the NPV of the project. If NPV is a function of all both deterministic and stochastic variables, the resulting NPV gets a range of values instead of a single value obtained in a conventional deterministic financial evaluation. NPV is obtained from the below formula.

$$
N P V=\sum_{n=0}^{N} \frac{C_{n}}{(1+r)^{n}}
$$

Where,

$\mathrm{ci}=$ the net cash flow in year $\mathrm{n}(\mathrm{n}=0,1,2, \ldots . \mathrm{n})$, represented by farm income in this study.

$\mathrm{n}=$ the planning period which equals fifteen years in the current analysis.

$\mathrm{r}=$ the discount rate.

Monte Carlo simulation is a computational algorithm designed to evaluate the variability or stochastic of the input variables of a model. It can be used to model the effects of key variables on the NPV of a given proposal. The process involves, first, the identification and assessment of the key variables. For each key variable, we fit a probability density function that best describes the range of uncertainty around the expected value. For this purpose, we used survey data at each MCC area and data from MAF Census 2013. The model including these variables is then calculated using randomly-generated input values taken from the underlying probabilistic distribution function. The computer model combines these inputs to generate an estimated outcome value for (NPV). The process is repeated (ten thousand times).

Monte Carlo simulation model is currently regarded as the most powerful technique for cash-flow analysis. It is useful when there are many variables with significant uncertainties. The more complex the project and the more risks and uncertainty that are associated, the more valuable Monte Carlo simulation analysis will be.

\subsection{Data collection}

Five MCC locations investment were evaluated in this study. This evaluation requires data on the revenue, operating and production costs and costs of capital for each MCC location. The milk collection volume and revenue for each MCC is estimated according to animal population and average milking yield at each location. Data used in this analysis were obtained from farmers face-to-face interviews during filed survey. 
Table 1. Camel milk production and feed of survey sample

\begin{tabular}{llll}
\hline Group / head & $\mathbf{1 - 5 0}$ & $\mathbf{5 1 - 1 0 0}$ & $\mathbf{1 0 0 >}$ \\
\hline Milk production & & & \\
Per group/ Lit & 22.03 & 36.25 & 30.57 \\
Per head/Lit & 6.5 & 7.47 & 6.47 \\
Animal feed & & & \\
Concentrate/group/Kg & 100 & 154 & 326 \\
Hay/group/Kg & 172 & 245 & 435 \\
Concentrate/head/Kg & 2.88 & 2.39 & 2.27 \\
Hay/head/Kg & 4.94 & 3.81 & 3.12 \\
Average head/group & 35 & 65 & 133 \\
\hline
\end{tabular}

Kheiry H. M. Ishag \& Abd Al Hamed Al Gasani, 2008.

The above table shows that farmers with big animal group more than 100 camels could not maintain enough cash to feed his animal due to marketing and market access problems. According to animal population and distance from MCC to Dairy plant five MCC locations were recommended. Milk volume, initial unit cost and good quality milk received by dairy plant were also estimated according MCC location.

Table 2. Stochastic variables affect project NPV and at different MCC locations

\begin{tabular}{lllll}
\hline Variables & Value & Min & Mean & Max \\
\hline Salalah Milk Collection & & & & \\
MCC capital cost RO & 210401 & & & \\
Stating time /year & 1 & & & \\
Initial unit cost RO & 0.181 & $85 \%$ & 0.190 & $135 \%$ \\
Initial price RO & 0.309 & $90 \%$ & 0.305 & $115 \%$ \\
Total milk collection/Lit/year & 803493 & $30 \%$ & 900000 & $110 \%$ \\
Early annual demand growth & $9.5 \%$ & $30 \%$ & $10 \%$ & $100 \%$ \\
Dairy Plant good milk received \% & $61 \%$ & $70 \%$ & $75 \%$ & $120 \%$ \\
\hline
\end{tabular}

\section{Garoun Hirity Milk Collection}

MCC capital cost RO

Stating time /year

Initial unit cost RO

Initial price RO

Total milk collection/Lit/year

Early annual demand growth

Dairy Plant good milk received \%
221332

$$
1
$$

$\begin{array}{llll}0.186 & 65 \% & 0.201 & 130 \% \\ 0.335 & 90 \% & 0.305 & 115 \% \\ 2036639 & 40 \% & 2051890 & 110 \% \\ 9.85 \% & 30 \% & 10 \% & 100 \% \\ 93 \% & 75 \% & 85 \% & 120 \%\end{array}$

\section{AL Haq Milk Collection}

MCC capital cost RO

Stating time /year

2

Initial unit cost RO

0.258

$85 \%$

0.225

$135 \%$

Initial price RO

0.295

$90 \%$

0.305

$115 \%$

Total milk collection/Lit/year

684660

$40 \%$

1043672

$110 \%$

Early annual demand growth

$8.88 \%$

$30 \%$

$10 \%$

$100 \%$ 


\begin{tabular}{lllll} 
Dairy Plant good milk received \% & $87.97 \%$ & $75 \%$ & $85 \%$ & $120 \%$ \\
\hline Tawi Ahater Milk Collection & & & & \\
MCC capital cost RO & 224375 & & & \\
Stating time /year & 2 & & & \\
Initial unit cost RO & 0.223 & $90 \%$ & 0.220 & $120 \%$ \\
Initial price RO & 0.303 & $90 \%$ & 0.304 & $115 \%$ \\
Total milk collection/Lit/year & 744969 & $30 \%$ & 750928 & $100 \%$ \\
Early annual demand growth & $9.86 \%$ & $30 \%$ & $10 \%$ & $100 \%$ \\
Dairy Plant good milk received \% & $92 \%$ & $85 \%$ & $90 \%$ & $120 \%$ \\
\hline Shahbi Asaeb Milk Collection & & & & \\
MCC capital cost RO & 270306 & & & \\
Stating time /year & 2 & & & \\
Initial unit cost RO & 0.248 & $90 \%$ & 0.250 & $120 \%$ \\
Initial price RO & 0.311 & $90 \%$ & 0.304 & $115 \%$ \\
Total milk collection/Lit/year & 644817 & $30 \%$ & 653510 & $110 \%$ \\
Early annual demand growth & $6 \%$ & $30 \%$ & $10 \%$ & $100 \%$ \\
Dairy Plant good milk received \% & $93 \%$ & $85 \%$ & $90 \%$ & $120 \%$ \\
\hline
\end{tabular}

Calculated by the Author.

Uncertain variables in simulation mode outlined and estimated in Table 2. Initial unit price, sale price, raw milk collection volume, percentage of good milk received at plant and capital cost of the MCC establishment were the main uncertain variables incorporated in the models. Table 3 shows a recommended MCC locations, animal population and distance from each MCC zone to Dairy plant at Salalah City.

The modeling process began by defining a series of inputs to describe the initial status and behavior of the project and farm system. The underlying behavior of the local milk marketing system was represented using current knowledge and recorded data from survey, MAF and literature. The purpose of qualitative risk analysis in this study is to provide a high level of understanding of risks of the MCC project. Such analysis may increase attention of project management and policy team members to the top risks they need to understand and manage effectively.

Table 3. MCC location, animal population and distance from Dairy plant

\begin{tabular}{llll}
\hline MCC location & Distance Km & Cow population & Camel population \\
\hline Garoun Hirity & 30 & 83658 & 36885 \\
AL Haq City & 60 & 50489 & 18191 \\
Tawi Ahater & 62 & 40004 & 9688 \\
Shahbi Asaeb & 90 & 16231 & 9624 \\
Salalah & 90 & 11304 & 5556 \\
& 15 & 83658 & 13311 \\
\hline
\end{tabular}

Dhofar Governance, MAF Census 2013.

The main risk and uncertainty variables identified in MCC Project were:

- Project capital increase and it is effect on NPV.

- Raw milk availability and it is effect on MCC yield and NPV. 
- $\quad$ Raw milk selling price volatility and it is effect on NPV.

- Cost of operation and it is effects on NPV and annual increase in sales price and unit cost.

- $\quad$ Total milk collection volume for year one and thereafter.

- Annual growth of milk collection for each MCC location.

- $\quad$ Percentage of good milk received at Dairy plant each year.

- Discount rate and it is effect on project viability and NPV.

The operation cost estimated according to total raw milk volume and distance between MCC and Dairy plant at Salalah City.

\subsection{SERF and Risk efficiency}

The analysis of investment decision of MCC needs entails understanding of how investors rank alternative MCC locations with uncertain outcomes, given the stochastic MCC milk yield for each center and the stochastic market price of milk. The economic evaluation of MCC is implemented considering the whole range of net present values (NPVs) and their associated probabilities, along with the relative preferences (utilities) of the decision makers. To assess and compare the economics and the risk efficiency of each MCC location, this study employs stochastic simulation as an unconventional method that incorporates risk in the analysis (Hardaker, J.B., 2004). Stochastic dominance and stochastic efficiency with respect to a function (SDRF and SERF) analyses have a major advantage in that they reduce the set of all possible risky choices to a small group of alternatives. The SERF technique is a novel improved methodology for assessing and ranking risky alternatives but empirical studies using SERF are limited, Especially in agriculture, SDRF and SERF analyses have been used to compare risky alternatives regarding farm production, marketing and financial matters. In this study, SERF analysis has been used to rank MCC locations and to determine risk efficiency of MCC locations, and also to explore the economic viability of MCC investment. However, this analysis will help in identifying best MCC location to start with and Government milk purchase subsidy required for each MCC location.

\section{Results and Discussion}

The study carried out by (HVA International, 2010), based on estimated cash flows, and showed that investment in MCC Project is only visible under Government price subsidy, since the $8 \%$ internal rate of return from that investment would be below the adopted $12 \%$ minimum rate of investment attractiveness. The previous study (Danielle et al., 2000), has not evaluated MCC locations risk in their study. However, this study investigated profitability for each recommended MCC location and incorporates risk of price paid to producer and milk collection volume for each MCC location in the analysis. Table 4 shows the result of simulated model for each MCC location and statistics.

The analysis shows that Garoun Hairity Location is highly profitable with RO 1723345 NPV and no risk of getting negative NPV and low Coefficient of Variation $0.402 \%$. Shahbi Asaeb location got a negative NPV under different discount rates i.e. (6\%-8\%-10\%-12\% and 14\%) and high Coefficient of Variation 1.190\%. The probability of getting positive NPV for this location is only $20 \%$ with $6 \%$ discount rate and reduced to $3 \%$ at $14 \%$ discount rate. Government capital subsidy for this location is highly required to mitigate risk and encourage investors and farmers to participate and benefit from MCC project.

\subsection{Cumulated Distribution Function (CDFs) Analysis}

The Cumulated Distribution Function (CDFs) analysis performed to illustrate the range and probabilities of NPV for different MCC locations. Figure 1 shows Garoun Hirity location is a superior location and has a high probability of getting positive NPV. However, CDF analysis shows that Al Haq City and Tawi Ahater MCC location are not first-degree or second-degree stochastically dominant as their CDFs lines crossed each other up to cumulative probability of $0.45 \%$ is reached and no clear ranking under different ARAC is possible. However, a more improved technics such as stochastic dominance and stochastic efficiency with respect to a function analyses can be used to rank alternative MCC location risk efficiently within specified range of ARAC values. 
Table 4. MCC recommended location compared to Salalah location - Statistics for NPVs for each scenario

\begin{tabular}{|c|c|c|c|c|c|}
\hline Models & Model (1) & Model (2) I & (3) & Model (4) & Model (5) \\
\hline \multirow[t]{2}{*}{ Location } & \multirow[t]{2}{*}{ Salalah } & \multicolumn{4}{|c|}{ Recommended MCC Location } \\
\hline & & Garoun Hairity & Al Haq City & Tawi Ahater & Shahbi Asaeb \\
\hline Mean & 579727 & 1723345 & 352000 & 261411 & $(115171)$ \\
\hline SD & 233264 & 692973 & 275022 & 162332 & 137473 \\
\hline $\mathrm{CV}$ & $0.402 \%$ & $0.402 \%$ & $0.780 \%$ & $0.620 \%$ & $1.190 \%$ \\
\hline Skewness & 0.483 & 0.5955 & 0.2470 & 0.344 & 0.0183 \\
\hline Kurtosis & 3.2598 & 3.476 & 3.170 & 3.061 & 3.096 \\
\hline Min & 30672 & 32957 & $(754000)$ & (189 000) & $(756000)$ \\
\hline Max & 1612876 & 5622000 & 1607209 & 892000 & 392000 \\
\hline Range & 1643848 & 5654957 & 2361209 & 1081000 & 1148000 \\
\hline
\end{tabular}

Calculated by the Author.

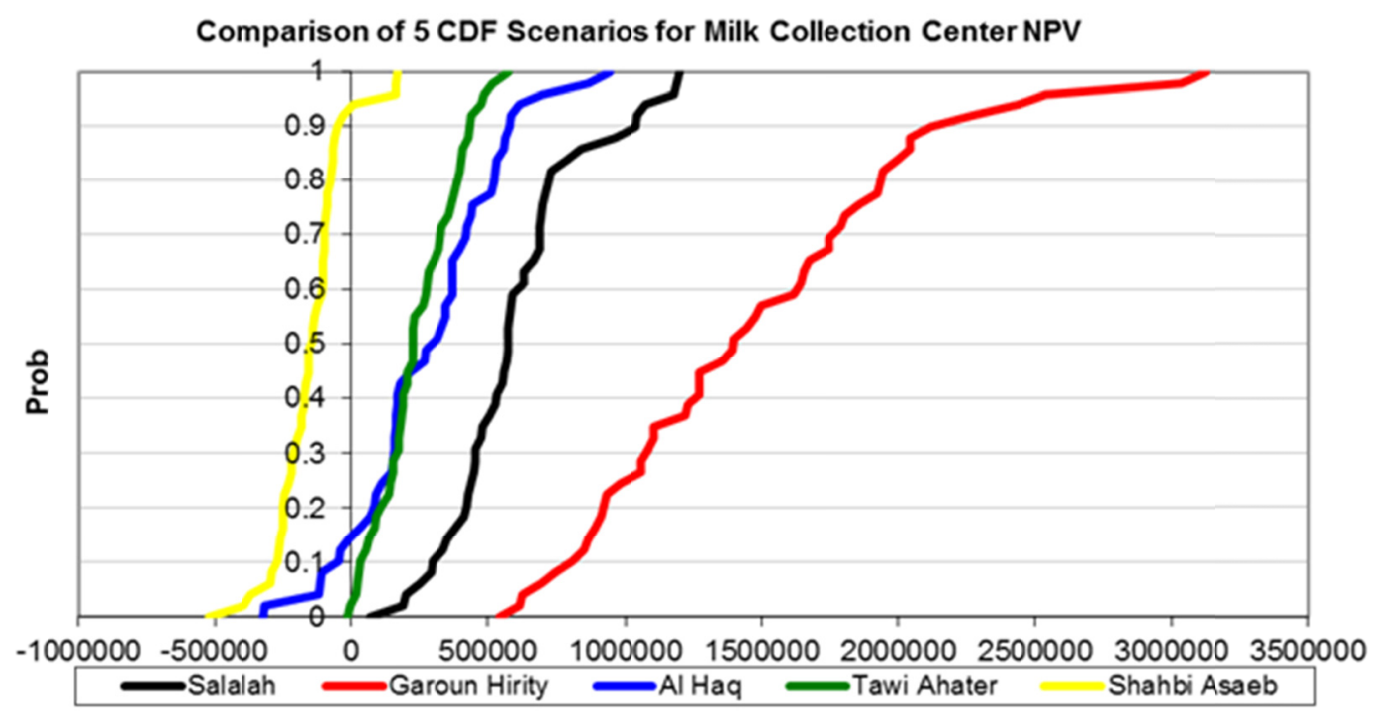

Figure 1. Cumulated Distribution Function CDF analysis of NPV for different MCC locations

\subsection{Stochastic Efficiency With Respect to a Function (SERF) Analyses}

The stochastic efficiency with respect to a function (SERF) analyses is performed to select and outline the risk efficient MCC location. The Excel Add-In SIMETAR developed by Schumann, Feldman, and Richardson (2011) was used to conduct the SERF analysis based on a negative exponential utility function. Certainty Equivalent graphs were constructed to display and rank NPV across the specified range of ARAC values. The risk premiums were also calculated for each MCC location by subtracting alternative NPV CE values from a preferred MCC location (Salalah NPV) CE values at given ARAC values.

In Figure 2 the SERF method is used to compare five MCC location alternatives simultaneously for a range of ARAC values between (0.00) and (0.0000014). The analysis shows and identifies Garoun Hirity location as a superior location followed by Salalah location and Al Haq City alternatives as the second and third risk-efficient location. The (SERF) analysis indicates that Garoun Hirity is the preferred MCC location for investors over the entire range of risk preferences. While NPV for Garoun Hirity range between 1472000 and 1304000 risk premiums between RO 749000 and 722000 must be paid to investors and farmer risk preference - to persuade them to switch from Shahbi Asaeb to Salalah MCC location the second-most preferred MCC. 


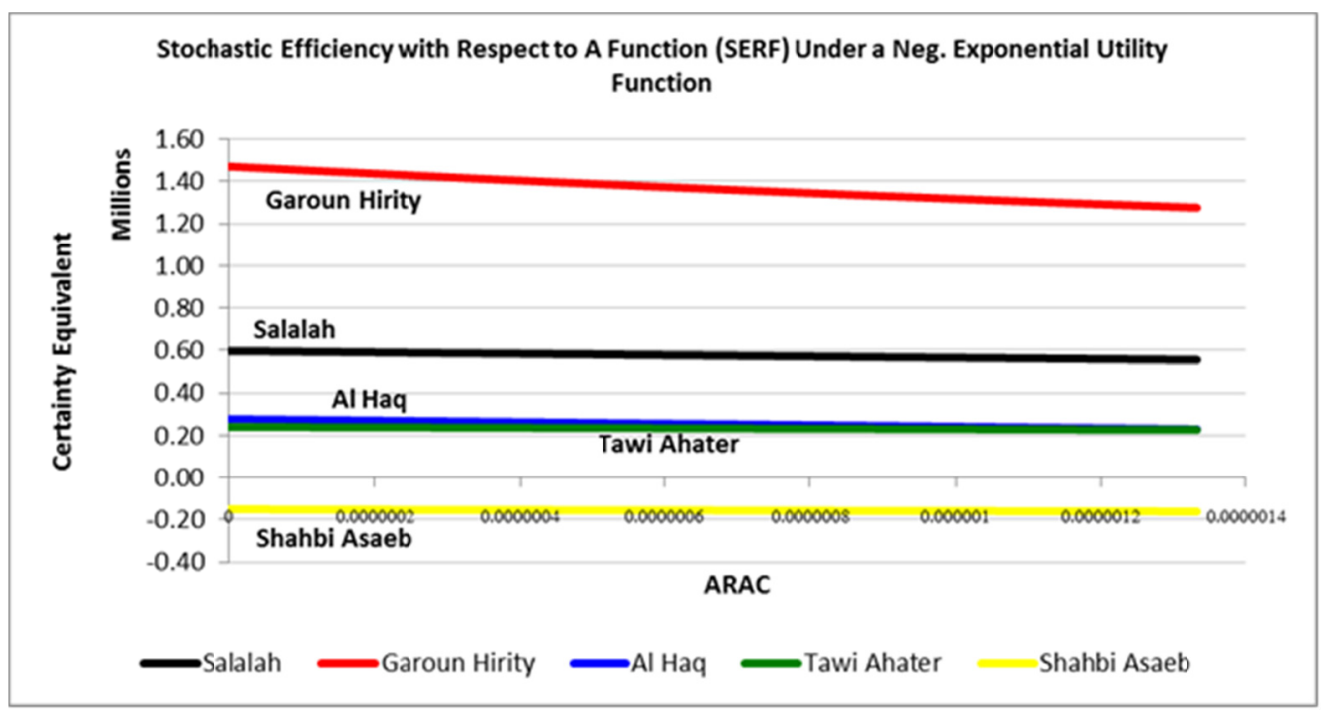

Figure 2. Stochastic Efficiency with Respect to a Function (SERF) of NPV for different MCC locations

The NPV of Garoun Hirity and Salalah location are visible under different Absolute Risk Aversion Coefficient, due to high animal population density and closer distance to Dairy Plant at Salalah City. The raw milk quality expected to be high and milk rejection percentage is low.

Table 5 calculates Certainty Equivalent CE for each MCC location across a range of ARAC. The calculated CEs are displayed on graphs, and the risky alternative with the highest $\mathrm{CE}$ at a particular RAC is the most preferred. Rankings five MCC risk alternative performed using SERF, over the range of risk preference, neutral to extremely risk averse, are presented graphically in Figure 2 and numerically in Table 5. Table 5 reveals that under all risk aversion level Shahbi Asaeb location required Government support to operate risk efficiently and encourage investors and farmers to participate in MCC project.

Table 5. Ranking of Risky MCC Alternatives by Risk aversion using CE for NPV (000)

\begin{tabular}{|c|c|c|c|c|c|c|c|c|}
\hline Risk degree & Risk Neutral & & Normal Risk & & Rather Risk & & Extremely $\mathrm{R}$ & \\
\hline ARAC & 0.00 & & 0.0000004 & & 0.0000008 & & 0.0000014 & \\
\hline Rank & Alternative & $\mathrm{CE}$ & Alternative & $\mathrm{CE}$ & Alternative & $\mathrm{CE}$ & Alternative & CE \\
\hline 1 & Garoun H. & 1472 & Garoun H. & 1398 & Garoun H. & 1334 & Garoun H. & 1304 \\
\hline 2 & Salalah & 598 & Salalah & 584 & Salalah & 570 & Salalah & 563 \\
\hline 3 & Al Haq & 278 & Al Haq & 262 & Al Haq & 246 & Al Haq & 238 \\
\hline 4 & Tawi A. & 241 & Tawi A. & 237 & Tawi A. & 232 & Tawi A. & 230 \\
\hline 5 & Shahbi A. & -150 & Shahbi A. & -153 & Shahbi A. & -157 & Shahbi A. & -159 \\
\hline
\end{tabular}

Calculated by the Author.

\subsection{Risk Premium and Willingness to Payment}

Risk premiums measure the value to be paid to a Decision Maker of one preferred alternative over a less preferred alternative, and are calculated by subtracting the $\mathrm{CE}$ of the less-preferred alternative from the $\mathrm{CE}$ of the preferred alternative at each RAC level. Because SERF generates CEs of the Decision Maker's preferences among alternatives MCC location at each risk aversion level, SERF can also estimate the utility-weighted risk 
premiums between alternatives MCC location. Figure 3 represent the difference between CEs represents what it would take for a Decision Maker to be willing to exchange the preferred location (Salalah) risky alternative for another less-preferred risky alternative. The value of WTP (willingness to payment) is calculated as the difference between the CE for a risky alternative and represents the payment necessary to make the farmers and investors indifferent between the less-preferred alternative and the preferred pilot location alternative at (Salalah) City:

$$
\mathrm{WTP}=\mathrm{CE} \text { preferred }-\mathrm{CE} \text { alternative }
$$

The SERF rankings and WTP are used to examine sustainability and analyze of deferent MCC locations. Figure 3 shows how the alternative location were examined in the study and ranked relative to the preferred (Salalah location) at various RACs. Table 6 shows the numerical risk premiums for four risk aversion levels.

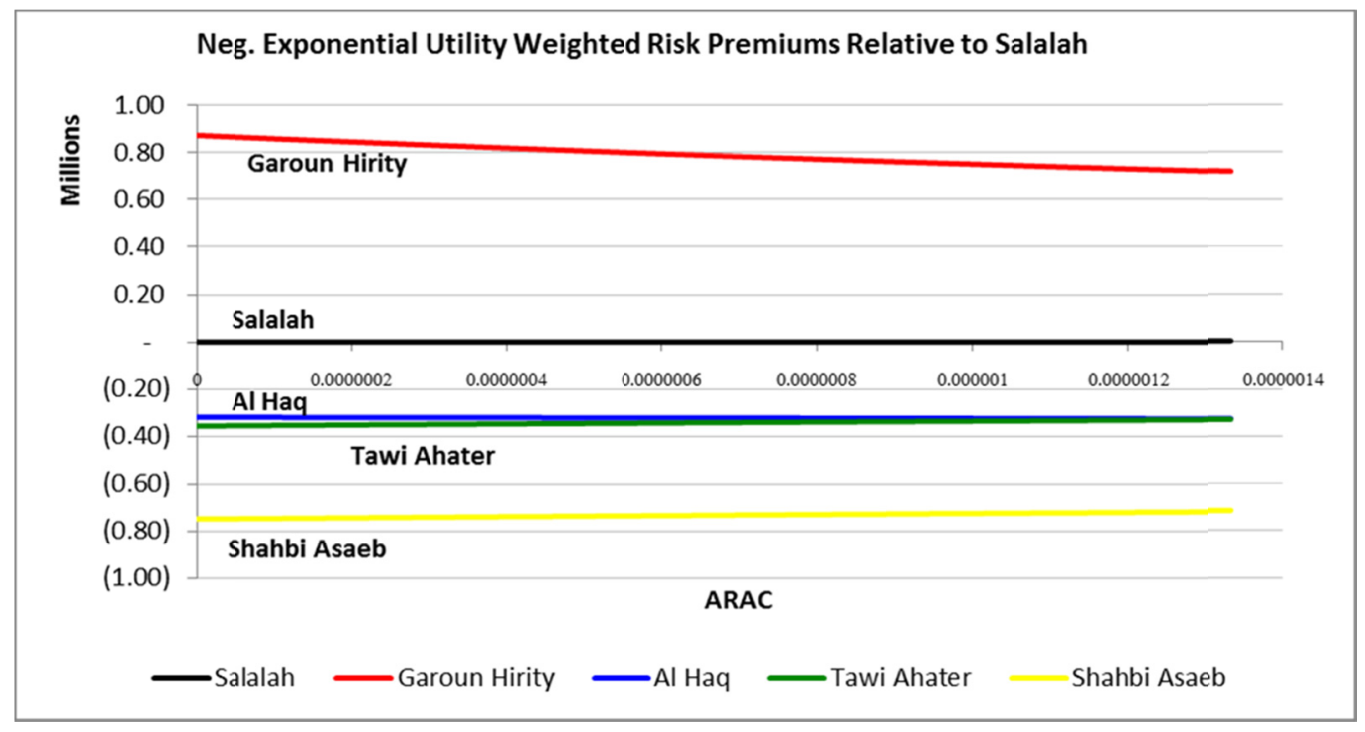

Figure 3. Present Risk Premium for MCC location relative to Salalah location

From Table 6, it is evident that Decision and policy Makers for the risk aversion levels examined have a small risk premium value between the preferred MCC location (Salalah) and the second alternative (Al Haq City) and large risk premium with Shahbi Aseab MCC location. Therefore, a more milk price has to be given to farmers and sufficient capital subsidy has to be given to investors at Shahbi Aseab MCC location to mitigate risk. The study also indicates that Garoun Hirity location is the most preferred location for all ARAC levels as shown in Figure 3. However, at risk neutral level RO 320 000, 357000 and 749000 incentives must be paid to Al Haq City, Tawi A. and Shahbi Aseab location respectively to be in the same position of the second-most preferred MCC location at Salalah. In general, the results of the SERF analysis indicate that Garoun hairity MCC location provide a useful risk-management tool for moderately to highly risk-averse farmers and investors.

Price paid to the farmer for milk is a risk-dependent item since it varies according to market conditions and milk composition. The dairy company can offer farmers bonuses and other awards linked to encourage the quality and/or volume of milk supplied. Variation of the price paid to the producer for milk and volume of milk produced on the farm were adopted for risk analysis: Sensitivity analysis found that these were the most unstable parameters of MCC project.

Volume of milk produced is another risk-dependent item since output depends on several factors, such as animal population at each location zone, climate \& rainy season, costs, and capital investments. Milk production in Dhofar Region is increases during the summer (rainy season) and decreases during the winter (dry season). This seasonal change is due to change in available pasture: more pasture in the summer, less in the winter. Farm investments to expand the herd, improve breeding stock, control diseases, and install milk cooling systems are economic factors that can contribute to increase milk production and assure raw milk quality. 
Table 6. Risk Premium NPV (000) of different MCC locations relative to Salalah location

\begin{tabular}{|c|c|c|c|c|c|c|c|c|}
\hline Risk degree & Risk Neutral & & Normal Risk & & Rather Risk & & Extremely R & \\
\hline ARAC & 0.0000 & & 0.0000004 & & 0.0000008 & & 0.0000014 & \\
\hline Rank & Alternative & $\mathrm{RP}$ & Alternative & RP & Alternative & $\mathrm{RP}$ & Alternative & $\mathrm{RP}$ \\
\hline 1 & Garoun $\mathrm{H}$. & 874 & Garoun H. & 814 & Garoun H. & 764 & Garoun H. & 741 \\
\hline 2 & Salalah & 0 & Salalah & 0 & Salalah & 0 & Salalah & 0 \\
\hline 3 & Al Haq & -320 & Al Haq & -322 & Al Haq & -324 & Al Haq & -326 \\
\hline 4 & Tawi A. & -357 & Tawi A. & -347 & Tawi A. & -338 & Tawi A. & -334 \\
\hline 5 & Shahbi A. & -749 & Shahbi A. & -738 & Shahbi A. & -727 & Shahbi A. & -722 \\
\hline
\end{tabular}

Calculated by the Author.

The risk premium calculation indicates that a range of RO (320 000-326 000) needs to be paid to Al Haq City location to be indifferent with Salalah location. For Tawi Ahater MCC location risk premium needs to be paid will range from RO (357 000-334 000) to be in same position of Salalah Milk Collection location. For Shahbi Asaeb location, the risk premium will range between RO 749000 to 722 000. However, Salalah Milk Collection is a preferred location to Dairy Plant as it is located near the dairy plant and milk can be transfared to the dairy plant immediately within two hours of milk collection from rural areas. The risk premium analysis also reveals that Certainty Equivalent $\mathrm{CE}$ for all recommended MCC locations remain constant across a range of selected ARAC in this research.

\subsection{Locations and StopLight Graph Analysis}

Stoplight graphs are simple graphical illustrations and show the probability of NPV being greater than a target value (35 000) and less than another target value (15 000) across risky alternatives. Stoplights are quickly interpretable, as they are read much like a traffic stoplight, in this case red is bad, yellow is marginal, and green is good (Richardson, Schumann, \& Feldman, 2006).

The probability of a risky alternative generating a net present value less than the lower bound value $(15000)$ is illustrated by a red region on a bar graph; thus, bad. The probability of an alternative generating a net present value greater than the upper bound value (35 000) is illustrated by a green region; thus, good. The region between the upper and lower bounds is yellow and shows the probability of NPV being between the upper and lower bounds.

The Stoplight graph in Figure 4 illustrates the probability of NPV being less than 15000 and greater than RO 35 000. Salalah and Garoun Hiriti locations have $100 \%$ probabilities of positive NPV, and Al Haq City has $82 \%$ whereas Tawi Ahater MCC location has $88 \%$ probability of positive NPV. The Stoplight analysis indicates that Shabhi Asaeb location has $92 \%$ probability of negative NPV, due to animal population at MCC zone and the long distance to Dairy Plant.

Investment in MCC Project with both the 10000 and 5000 liter milk cooling tanks would be feasible and attractive, since their NPV are positive and return in investment (RI) would be significantly above the opportunity cost of capital for all recommended MCC location except Shabhi Asaeb location. Sensitivity analysis, in turn, revealed that an increase of $25 \%$ in the incentive paid to farmers for supplying cooled milk (increasing initial price from 0.304 to 0.380 ) would be sufficient to make the MCC investments attractive, and increase probability of getting positive NPV to $99 \%$ at $6 \%$ discount rate and to $88 \%$ at $14 \%$ discount rate for Shahbi Aseab MCC Location.

The result also indicates that the risk of MCCs investment failure can be reduced by selecting MCC location near to Dairy Plant and with large animal population size. The cost of MCC operation and milk volume were the main factors affecting profitability and insure project sustainability as shown by sensitivity analysis. 


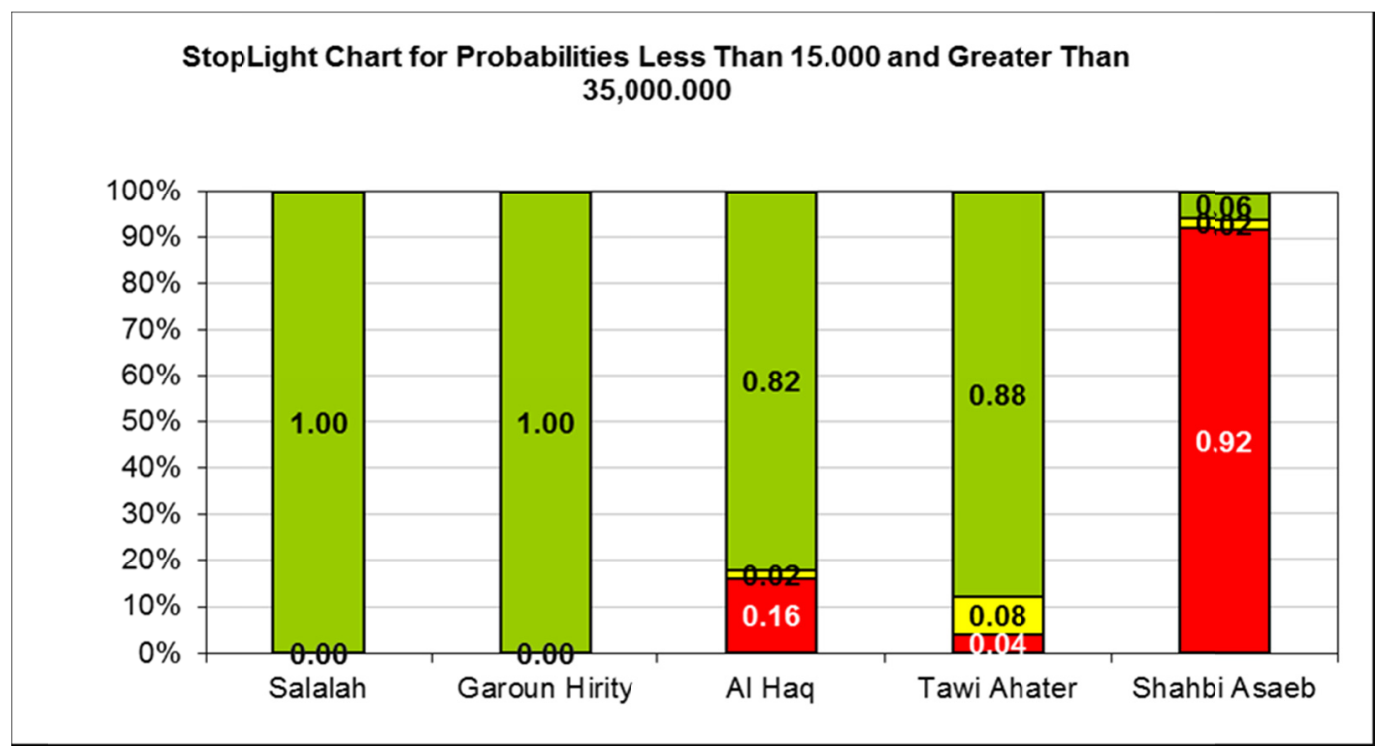

Figure 4. StopLight chart for NPVs of four MCC location compare to Salalah pilot MCC location

\section{Conclusions}

Investment in different MCCs locations were tested by using dynamic location analysis and incorporating milk volume and milk price risk in the analysis. Risk analyses for the establishing MCCs with 10,000 and 5,000 Lit cooling tanks at four recommended locations were tested and reveal profitability except for Shahhbi Asaeb location. The dynamic risk analysis of this investment shows low probability of getting positive NPV of less than $20 \%$ at $6 \%$ discount rate and reduced to $3 \%$ at $14 \%$ discount rate. Incentive price increase of $25 \%$ given to MCC at Shahbi Asaeb location can increase probability of getting positive NPV to $99 \%$ with $6 \%$ discount rate.

The results also indicate that the risk of MCCs investment failure (an increase in profitability of negative NPV) is reduced by the potential for increased milk production at rural area. Conversely, capital requirements will restrain small farmers to invest in upgrading farm facilities and herd improvement investments. This restraint and difficulties faced by small farmers when trying to increase production will probably lead to the exclusion of a significant number of small farmers from the formal dairy product market as the demand for cooled milk delivery by dairy industries grows. As a result, Ministry of Agriculture \& Fisheries needs to imposed regulations and implemented herd improvement programs. Moreover, raw milk price incentive needs to be implemented by Government Authorities.

Current social concerns and the fast pace of Oman dairy business modernization suggest that the installation of MCC and cooling tanks will become essential to the survival of dairy plant industries and farmers. It appears that dairy industries will increasingly demand cooled milk transported in isothermal tanks. Therefore, the sustainability strategy recommended for small dairy farmers is to increase milk production by increasing yields through the adoption of herd nutrition and breeding management technologies.

\section{References}

Barham, E. H., Robinson, J. R., Richardson, J. W., \& Rister, M. E. (2011). Mitigating cotton revenue risk through irrigation, insurance, and hedging. Journal of Agricultural and Applied Economics, 43(4), 529-540.

Bryant, K. J., Reeves, J. M., Nichols, R. L., Greene, J. K., Tingle, C. H., \& Studebaker, G. E. (2008). Valuing transgenic cotton technologies using a risk/return frame work. Journal of Agricultural and Applied Economics, 40(3), 767-775.

Danielle, D. S. A., Carlos, A. B. S., \& Sebastião, T. G. (2000). Risk analysis of investments in-farm milk cooling tanks. Rev. Econ. Sociol. Rural, 41(2). http://dx.doi.org/10.1590/S0103-20032003000200005

Eschenbach, T. G. (1992). Spiderplots versus tornado diagrams for sensitivity analysis. Interfaces, 22(6), 40-46. http://dx.doi.org/10.1287/inte.22.6.40

Gouse, M., Piesse, J., Thirtle, C., \& Poulton, C. (2009). Assessing the performance of GM maize amongst smallholders in KwaZulu-Natal, South Africa. AgBioForum, 12(1), 78-89. 
Hardaker, J. B., Huirne, R. B. M., Anderson, J. R., \& Lien, G. (2004b). Coping with Risk in Agriculture (2nd Edition). Wallingford: CABI Publishing. http://dx.doi.org/10.1079/9780851998312.0000

Hignight, J. A., Watkins, K. B., \& Anders, M. M. (2010). An economic risk analysis of tillage and cropping systems on the Arkansas grand prairie. Paper presented at the Southern Agricultural Economics Association Annual Meeting, Orlando, FL.

Kheiry, H. M. Ishag, \& Abd, A. Hamed. A. Gasani. (2008). Animal Husbandry Survey Report - Dhofar Directorate General of Agriculture \& Fisheries- Ministry of agriculture and fisheries- sultanate of Oman.

Pendell, D. L., Williams, J. R., Boyles, S. B., Rice, C. W., \& Nelson, R. G. (2007). Soil carbon sequestration strategies with alternative tillage and nitrogen sources under risk. Applied Economic Perspectives and Policy, 29(2), 247-268. http://dx.doi.org/10.1111/j.1467-9353.2007.00341.x

Ribera, L. A., Hons, F. M., \& Richardson, J. W. (2004). An economic comparison between conventional and no-tillage farming systems in Burleson County, Texas. Agronomy Journal, 96(2), 415-424. http://dx.doi.org/10.2134/agronj2004.0415

Savvakis, C. S. (1994). Risk analysis in investment appraisal. Project Appraisal Journal, 9(1), 3-18. http://dx.doi.org/10.1080/02688867.1994.9726923

Schumann, K. D., Feldman, P. A., \& Richardson, J. W. (2011). SIMETAR O: Simulation \& econometrics to analyze risk. College Station, TX: Agricultural and Food Policy Center, Texas A\&M University.

Szekeres, S. (1986). Considering uncertainty in project appraisal (p. 60). Washington, USA: International Bank for Reconstruction and Development.

White, J. A. (1998). In K. E. Case, D. B. Pratt \& M. H. Agee (Eds.). Principles of engineering economic analysis. (4th ed, p. 491), New York, USA: John Wiley \& Sons.

Williams, J. R., Pachta, M. J., Claassen, M., Roozeboom, K., \& Llewelyn, R. (2011). Wheat stubble to burn or not to burn: An economic analysis. Western Economics Forum, 10(1), 32-42.

\section{Copyrights}

Copyright for this article is retained by the author(s), with first publication rights granted to the journal.

This is an open-access article distributed under the terms and conditions of the Creative Commons Attribution license (http://creativecommons.org/licenses/by/3.0/). 